\title{
Investigating the Influence of Setting on Language Learning: The Case of Bahdini Kurdish Learners of English
}

\author{
Ivan Hasan Murad \\ MA in TESOL, Department of English language, School of Humanities, \\ University of Zakho, Kurdistan Region, Iraq \\ Khalif Abdulrahman Al-Jumah \\ MA in TESOL, English Department, Cihan University-Duhok
}

\section{Hozan Gorgeen Othman}

MA in Linguistics and Language Acquisition

Department of English language, School of Humanities,

University of Zakho, Kurdistan Region, Iraq

doi: 10.19044/esj.2017.v13n8p272 URL:http://dx.doi.org/10.19044/esj.2017.v13n8p272

\begin{abstract}
It was argued that those learning the language while mingling with the community are better learners than those learning in the academic setting where they only opt to use the academic language. The current small-scale study investigates the influence of the setting on two Bahdini Kurdish learners of English living in the UK in two different contexts. One of the learners has been learning English in an academic setting, while the other has been learning English through daily interactions with the community in a non-academic setting. Data were collected through interviews and observation. Results revealed that both learn English effectively for the context where their language will be used. However, the academic language learner was capable of expressing himself more than the one learning the colloquial language. The academic learner could use a variety of strategies to express different situations and had a clearer language than the one learning the colloquial language even though the academic language learner did not mingle with academicians like the colloquial learner did with the community.
\end{abstract}

Keywords: First Language Acquisition, Second Language Learning, Errors, Interference, Interlanguage

\section{Introduction}

The internationalization of English and the increasing number of English learners has enhanced the interest in investigating the interlanguage 
of English learners. Linguists differed in their interpretations of the process of second language (L2) learning. Troike (2006) defines second language acquisition (SLA) as the process of learning a language at a specific time in life after the L1 has been learnt. Gass and Selinker (2001) and Ellis (1997) agree that SLA is the process of learning an L2 after learning the L1. They also agree that even though it is 'L2', it does not necessarily mean that it is the second language that the person has learnt, rather it could refer to the learning of a third or fourth language that the person is learning. Additionally, Ellis (1997) goes on suggesting that "'second' is not intended to contrast with 'foreign'" (p: 3).

Troike (2006) states that "SLA involves a wide range of language learning settings and learner characteristics and circumstances” (p.5). These factors differ from a learner to another since each learner has his own way of learning. L1 background can be very helpful in learning an L2. However, learners need to be aware of the differences between their L1 and L2 (Lightbown \& Spada, 2006).

Kachru (1992) classified the world Englishes into three different categories labeled as Inner, Outer and Expanding Circles (cited in Karen, 2011). In his categories, he referred to the UK, Canada, the United States, New Zealand and Australia as the 'Inner Circle' in which English is the main spoken language and referred to these countries by the acronym (ENL), which stands for English as a native language. Followed that the 'Outer Circle' by which he referred to the countries where English is used as an official language and named it English as a second language (ESL). Lastly, the 'Expanding Circle' comprises of the countries where English is used as a foreign language and referred to it as (EFL) (Mullany \& Stockwell, 2010).

There have also been many prophesies about the future of English. Crystal (1997) is very optimistic about its future. He wonders whether English will be the only language of the globe in 500 years, adding if the effect of English continues, the globe will conceive a probable intellectual progression and English then might become the only language spoken (as cited in Harmer, 2001). Graddol (1997), on the other hand, suggests that the effect of global English might decline for certain reasons. He justifies his position in light of the fast growth of Hispanic language in both South and North American continents, indicating that a time might come when these two continents become bilingual-English-Spanish speaking areas. He also predicted that Mandarin might become widely used in Asia if Chinese travel services dominated the world airline services and if their internet computer websites and other services over took other computer hosts (cited in Harmer, 2001). However, nowadays, it can be argued that English is widely used globally, which makes it the international language. Therefore, the current 
paper tries to investigate the ways two distinct Bahdini Kurdish ESL learners learn English language.

\section{Literature review}

In 1959, Chomsky published a strong attack on Skinner's verbal behavior that changed the impression of linguists and psycholinguists to consider the idea of behaviorism as inappropriate. In that, Chomsky (1959) argued that behaviorism was unsuccessful in explaining the logical problem of acquiring languages. He added, children develop their language not only through copying and mimicking what is heard, since the language children are exposed to is incomplete and lacks grammatical features, yet they distinguish between the correct and incorrect ones (Lightbown \& Spada, 2006). Thus, his nativist attempt controlled over psycholinguistics and his Universal Grammar (henceforth UG) approach consolidated that language learning is not based on Stimulus-Response-Reinforcement (S-R-R) process (Dickins \& Dickins, 2001). In his UG, Chomsky (1959) holds that there are certain sets of rules within the mind of human beings which help them acquire the language and that these rules are available in all languages which makes it is similar to each other, which in turn are referred to as 'Principles and Parameters' (Mitchell \& Myles, 2006).

Troike (2006, p: 47) purports that "Chomsky and his followers argue that children come to the task of acquiring a specific language already possessing general knowledge of what all languages have in common, including constrains on how any natural language can be structured". Chomsky (2002) stated that the ability by which children can acquire a language is the language acquisition device (henceforth LAD), which is the part of the human brain that does all the process of language acquisition. This LAD needs a comprehensible input to enhance the process of language acquisition (Ellis, 1997). As for SLA, Troike (2006) and Setter and Jenkins (2005) suggested that if the parameter settings of L1 and L2 are same, positive transfer will take place, whereas if they are different then interference will probably occur.

Then, when learners try to use what they have learnt of L2, interlanguage is developed (Selinker, 1972). Learners come up with mixed structures of their L1 and L2, and these structures are neither in L1 nor in L2, but rather chunks of unreal structures that are made up as a result of the mixture of structures of L1 and L2 (Ellis, 1997; Rutherford \& Thomas, 2001). Because "parameter settings and mastery of morphological features" are only related to L1 acquisition, it is difficult for L2 learners to master these features (Troike, 2006, p: 47). Thus, such difficulty leads them to be fossilized at a certain stage, which clearly falls short of high levels like native speakers (Troike, 2006). He adds that errors are also caused by 
incomplete learning of L2 and believes that L2 learners' errors are developmental ones and are referred to as intralingual errors. Han (2004, as cited in Fidler, 2006) sees that it is difficult for most L2 learners to progress in learning the target language. Thus, the scale of their progression seems to become invisible even if they continue to be exposed to the target language in different ways like classroom or using the language in daily communication.

These attempts constrained linguists to concentrate on L2 learning and come up with new assumptions. Krashen's (1982) monitor model was another attempt in explaining L2 learning; it consisted of five hypotheses as follows:

1- The acquisition-learning hypothesis

2- The monitor hypothesis

3- The natural order hypothesis

4- The input hypothesis

5- The affective filter hypothesis.

The first one holds that language acquisition occurs unconsciously, like the way children acquire their L1, while learning a language occurs consciously and learners are aware of what they are doing (Lightbown \& Spada, 2006). The second one suggests that our conscious learning is in charge of monitoring and amending what we produce as a result of acquisition, which is the only "function" that learning does (McLaughlin, 1987).

Krashen's third hypothesis states that, we acquire the language in a fixed sequential order, and the easiest aspects of the language are not necessarily the first to be acquired (Krashen, 1985). The fourth hypothesis purports that learning happens when L2 learners are exposed to understandable input, which consists of structures that are slightly more difficult than their present level and also with the help of the contextual meaning (Krashen, 1985, as cited in Xu \& Fang, 2010). Krashen's last hypothesis states that when learners are exposed to large quantity of understandable input, they will not necessarily acquire much knowledge of the language they are exposed to. He argues that this is attributed to their personality that is affected by the "affective filter," which is a kind of hurdles that block the LAD from storing this input. Affective filter can be activated by factors such as high level of anxiety, low motivation and lack of selfconfidence (Lightbown \& Spada, 2006).

In addition to Krashen's hypotheses, some other SLA hypotheses are proposed. The Interpretability Hypothesis and the Variational Learning Hypothesis are two relevant ones. Predictions of these hypotheses could be tested in the present study. According to Tsimpli and Dimitrakopoulou (2007) the Interpretability Hypothesis predicts that the learners in our case 
studies will not be able to fully reset the parameter that corresponds to English because the features involved in their derivation are interpretable at the logical form, and therefore Behdini-based structures will continue being over-used in their English interlanguage.

Additionally, the Variational Learning Hypothesis predicts that the optionality patterns of Behdini (i.e. the structures that are similar to English and those that are different) will be transferred into the interlanguage of the L2 learners of English (Slabakova, 2008). Those two hypotheses will be test in the current study.

\section{Methodology}

This section presents the participants in the study in much details and also gives a brief description of study design and the way data were collected along with justifications.

\section{Participants}

The two participants are assignment pseudonyms. One of the participants is named Ahmed. His L1 is Kurdish. He is 24 years old. He was taught English when he was in the primary, secondary and high school, but in a very poor and superficial way. When he arrived in the UK, he was enrolled in a full-time English course at Kirklees College. He studied there only for five months. During that period, he passed the beginner, intermediate (each level lasted for seven weeks) and only two weeks of the upper-intermediate level. Then, he took an IELTS test and achieved an IELTS band 4.5, which is generally considered as high. Side by side with his course, he used to listen to English music, watch English films, and go to gym. He had some English friends in the gym, where he used to speak to whenever he went there.

The second participant is also Kurdish. His pseudonym name is Bakhtyar. He is 30 years old. He has been living in the UK for nearly nine years. He speaks four languages; Arabic, Turkish, Kurdish, and English. When Bakhtyar arrived in the UK, he was obliged to enroll in a language course to learn English, but soon he left it. He moved from a place to another seeking for a job. He finally found a job in a restaurant where he has been working ever since. He used to work from $7 \mathrm{am}$ to $8 \mathrm{pm}$, five days a week. There he made English friends and began to interact with English people.

\section{Areas of analysis and methods of data collection}

This study primarily focuses on some mistakes that the chosen case studies have made. It also concentrates on the ways they use English language, i.e. formal/informal, and links these areas to the theories of learning language. Different methods have been used to collect data. Owing 
to the participants' limited time and because of the time constrains as it was very difficult for the researchers to keep contacting them, researchers had to depend on a small amount of data and deeply examine them.

\section{Interviewing technique}

An interview is a conversation between two or more people where questions are asked by the interviewer to elicit facts or statements from the interviewee (Punch, 2009). It is also defined as a qualitative research technique which involves "conducting intensive individual interviews with a small number of respondents to explore their perspectives on a particular idea, program or situation" (Boyce \& Neale, 2006, p.3). According to Oppenheim (2000), interviewing technique is useful to obtain detailed information about personal feelings, perceptions and opinion. It allows more detailed questions to be asked. It usually achieves a high response rate. Through interviewing technique ambiguities can be clarified, incomplete answers can be followed up, precise wording can be tailored to respondents and precise meaning of questions are clarified. However, Cohen et, al. (2007) state that interviewing technique can be very time consuming: setting up interviews, transcribing, analyzing, feedback, reporting may take long time.

Interviews were recorded. This helped the researchers refer to the data whenever they needed it, especially with Bakhtyar who was unable to write.

\section{Observation}

According to Robson (2011), observation is a crucial qualitative data collection method through which the researchers observe what participants do and say. This technique is utilized as it is argued that conducting observations and interviews together reinforces the qualitative data of the research (Denscombe, 2007). However, this technique has its own limitations too. It is time consuming, writing notes is cumbersome and also they could be written subjectively (Hennink et al, 2011).

\section{Discussion andAnalysis}

This section is devoted to analyze some of the mistakes that the case studies have made when they used their L2. It also touches upon their positive and negative learning characteristics, which have a great role in learning an L2.

\section{Ahmed}

Ahmed said the following incorrect sentence ; 


\section{-I did not received it.}

The subject has been taught the structure of the past tense in his course, yet he made this mistake and many of this kind even though the researcher was correcting them for him every time he made such mistakes. As it is clear, the subject wanted to say 'I did not receive it'. For such an error, evidence (Selinker, 1972) suggests that this kind of mistake could be interlanguage related. His L1 is Kurdish and if this sentence is translated into Kurdish, it would be: [mnnawargrtbo] which literally means (I not received it) in English. The subject used 'did not' and added 'ed' to the verb 'receive', so [bo] in [wargrtbo] stands for the past tense in Kurdish, which equals the 'ed' in English. This mixture in structures creates a new irrelevant structure which is neither English nor Kurdish. Another cause for such an error could be the unwillingness of correcting oneself. As mentioned earlier, he has been taught this tense more than once, yet he continues making such a mistake, which means that he might be aware of it and does not bother himself correcting it. So, this might suggest that his language has fossilized and that he is not willing or able to progress to a further stage. This could be also linked to the idea of not monitoring oneself when using the target language because his intention could be just to pass the message on and not the way of saying it.

Another error which was noticed in the piece of Ahmed's writing is as follows; not bad.

- The teacher they taught us one of them was good and another

There are some mistakes made in this sentence. One of them is the part 'and another not bad'. There is a possible sense of transference in this part. It could be a typical Kurdish phrase in the meaning and form. If it is translated into Kurdish, there will not be any difference in the form and meaning as well, whereas the sentence structure of English and Kurdish are distinct. So, this could be due to his L1 transference, which is, using Kurdish language rules when talking in English language which leads him to make such mistakes. This is supported by the Variational Learning Hypothesis and Interpretability Hypothesis, which predicted such L1 rules transference to L2.

Ahmed also misused 'articles' which are not used in Kurdish. This might be because the subject has stopped changing the rules which he has acquired from his L1 and applies them when he speaks English language. Thus, it seems that his L2 has fossilized, because he does not show any progression regarding the difference between the rules of Kurdish and English languages. Mixing between two distinct structures of L1 and L2 is what Ahmed has done in this sentence. So, taking the sentence as a whole 
could be apossible evidence of interlanguage, where the rules of both Kurdish and English are applied.

Another assumption to such a mistake is that the subject might know the correct form of the sentence but due to the pressure of the time, he could not monitor himself when writing his sentence. Thus, he used the wrong form unconsciously. Hence, there were not any factors triggering his conscious part of the mind, which is responsible for monitoring, checking and editing such mistakes. On a formality level, there is a sense of informality in using "not bad" in this context. Normally, in English "not bad" in such contexts, is used in spoken English.

Another main point worth mentioning is the pronunciation issue, which the researchers noticed when interviewing the participant. In fact, Kurdish language has some sounds in its phonetic system that are not available in English phonetic system and vice versa (Dovaise, 2010). This is another fact that adds more difficulty to the learning of English for most of Kurdish learners who are trying to learn English as a second language unless they have been learning English for a long time. Adding to that, the fact that Arabic is his L2 and that it contains the uncommon sounds of both Kurdish and English. Therefore, the sounds that he has difficulty with seemed to be the uncommon sounds of both languages. The below examples of his pronunciation make it clear that he is one of those students who face difficulty pronouncing uncommon sounds (Dovaise, 2010), as follows:

Sentence/word

- I saw something there

- Most of the time

Because there is neither / $\theta$ / nor / ð / in Kurdish sound system, the subject had much difficulty pronouncing any English words or sentences containing one of these sounds. Moreover, this would confuse him even pronouncing the rest of the sentence or word. However, these sounds were sometimes pronounced correctly by him, but that was when he used to over monitor his pronunciation according to Krashen's monitor hypothesis. It was also noticed that he used to avoid questions that involved mentioning these sounds. Thus, he was very slow in speaking, i.e. being very careful and over monitoring his pronunciation were the main reasons of not being fluent in speaking and reading as well.

This process also drove Ahmed to pronounce the word in a new way that was neither correct in English nor in Kurdish. This could be because of Intralingual, that is, a stage of development in the process of attempting to produce the correct sound. Such pronunciations are made by Ahmed when he is very concerned about the content of the message rather than the pronunciation which in turn deviates him from monitoring himself. So, 
evidence (Krashen, 1985) suggests that such errors might be as a result of not monitoring himself, which makes his pronunciation errors clearer. Thus, it could be very difficult for him to change his pronunciation and add the uncommon sounds to the system he already possesses. $\mathrm{CPH}$ could also support this argument as the reason is his age which is beyond the age of puberty (Ellis 1997). He is already 24 years old which according to some linguists it makes it difficult for him to acquire or adjust his pronunciation.

Since Ahmed is a student and learns English for his own special purposes, his personality has much effect on his learning style and on the process of his language learning as well. Throughout the interviews and the time spent living together, it seemed that Ahmed's personality and motivation had some contradicting points. He seemed to be an extroverted and spontaneous person and loved meeting and speaking with people. So, his desire for communication seemed to be huge, which in turn triggered his aptitude for learning English. However, his anxiety, nervousness and fear of making mistakes when speaking seemed to inhibit the process of his language learning to some extent. It was noticed that when he spoke in English he was very careful and worried about the mistakes he would make. This could have a great effect on his fluency because he cared much about his accuracy as his IELTS target was 6.5.

\section{Bakhtyar}

Bakhtyar, who has been in the UK for nearly nine years, is the second case study. Throughout the discussion about English language, it seemed that his attitude towards English language is positive and that he sees that learning English is very useful for everyone since English has become the global language. According to the interaction hypothesis, it was deduced from his speech that living with Kurdish people in the same house has been his major issue of not mastering the spoken English and thus being unable to attain a native like level. However, there has been a compensation for that, because his English friends have been of much support to him in learning English.

One of the common errors that Bakhtyar made while communicating in English is as follows:

\section{Sometime I am not see him.}

In this sentence, the subject has used verb 'to be' instead of using verb 'to do' when he used to talk about an action. This suggests that he is unaware of the verb to use because he has not been taught the rules of using these kinds of verbs. He might not have learnt it from the society, because English people do not use it, but rather it could be of his own creation. Evidence (intralingual errors) suggests that this could be a generalization of the use of 
verb 'to be' which is related to the stages of development L2 learners go through.

Another assumption for such an error could be because he was thinking in Kurdish and speaking in English and used Kurdish sentence structure. So L1 transference might be the cause for that, because if this sentence is put in Kurdish, there will not be much difference in the structure and meaning as well. The overuse of this kind of verb might have caused Bakhtyar to fossilize as a result of not being corrected by the people around. As a result, he might have thought that it is correct, thus he kept using it.

The way Bakhtyar used to interact with his costumers at work shaped his language in two ways which are: using a relatively short sentences and phrases, on one hand, and using a kind of formal language, on the other. He used the former (lack of grammatical features) shape with his work mates and that was because of the nature of his work which required him to be quick in dealing with costumers. Therefore, his focus was only on the key words which used to convey the full meaning of his message. A good evidence of his use of short phrases is as follows:

When I go work, he at home. When I come back he sleeping.

You go home, you very happy.

This kind of error could be as a result of the argument made above. Thus, he might be fossilized and the reason could be the nature of his social context which had a great effect on the progression of his language. The main focus was on the message and not on the form. Thus, his language was shaped in this way. On the other hand, he used to use formal questions when he used to deal with his costumers, for example:

\section{What can I do for you?}

What would you like to have?

This was the positive side of using the language as English people tend to be politer in their speech. Moreover, phrases like; "whatd'ya' want? Hi! Wazgoin' on", were also used at work especially with his close friends as a result of the environment and the people he worked with. This could be to show that he is acculturated with them. Evidence (Ellis, 1997) suggests that such formulas help the learner to develop a kind of fluency. So, his social context had a great effect on the growing shape of his language.

Regarding the pronunciation level, according to Tedova and Cenoz (2009), being a multilingual speaker is a good factor of having a good pronunciation. Bakhtyar did not have any difficulties pronouncing any sound in English as he knew four languages. Nevertheless, he used to pronounce phrases and words just like the way English people do in a kind of informal way, such as:

That one

/da wAn/ 
Leaving out the /t/ sound as in words like "letter, bottom, matter"...etc. is another issue in his pronunciation. The reason for this could be his friends and the society he lives in, because these are the only sources where he learnt his L2. Therefore, by using such pronunciations, it could be argued that he might be fossilized as a result of the continuous usage of such pronunciations which is why he did not know the exact pronunciation.

Due to the shortage of space, Bakhtyar's learning factors had to be briefly explained. It seemed that one of the enhancing factors of his language leaning is his personality. The kind of intimate relationship and the interaction that he had with his English friends planted a desire of communication in him through which he could improve his language. As a result, his aptitude for leaning became high and he used to communicate normally. Results from observation suggest that when Bakhtyar used to communicate, he did not feel anxious or worried about his English language as Ahmed used to feel. Thus, there was nothing inhibiting his language learning. As a social being, being surrounded with helpful and trustworthy friends, his motivation for learning and communication reached a high level. According to some linguists, age also has an important role in learning an L2. Bakhtyar is now nearly 30 years old which might negatively affect his language development, taking the period he lived in the UK into consideration, he still used to make mistakes.

\section{Conclusion}

Language is not only learnt in the classroom, but by integrating with the people using it. Daily interaction may be insufficient, but it useful. Thus, Ahmed's aim to achieve professional goals moved away from acquiring the social language to acquiring the academic language, which is of much difficulty to him. While, Bakhtyar did not seem to have serious problems learning the English language, because he did not have to fulfill any goals apart from effectively using the language to communicate with people,which in turn did not create any tension in him while learning it. Learning anything in a relaxed way will be more effective than learning it with much tension and stress. Bakhtyar did not have any tension in that, while Ahmed's tension was the hindrance in his language learning. Ahmed's pronunciation tended to be more academic than Bakhtyar's colloquial one.

Both Ahmed and Bakhtyar have transferred L1 features into their interlanguage meaning that they have not been able to fully reset the English parameter. This is in line with the predictions of the Interpretability Hypothesis. However, both case study learners have also successfully used structures that correspond to English, and this can be interpreted by the predictions of the Variational Learning Hypothesis mentioned above. 


\section{References:}

1. Bavin, E. L. (2005). First Language Acquisition. Language in Society. June. $34 \quad$ (3), pp. 474478[online]availablefrom:proquest.[http://search.proquest.com.libacc ess.hud.ac.uk/docview/204587436?accountid=11526].

2. Bongaerts, T. (2005). Ultimate Attainment and the Critical Period Hypothesis for Second Language Acquisition: International Review of Linguistics in Language Teaching.43(4),pp.259267.[online]Available

from:proquest.[http://search.proquest.com.libaccess.hud.ac.uk/docvie w/204971156?accountid=11526].

3. Chomsky, N. (2002). On Nature and Language. Cambridge: Cambridge University Press.

4. Dickins, E. T. and Dickins, W. D. (2001). Symbols, Stimulus Equivalence and the Origin of Language. Behavior and Philosophy. 29, pp. 221. [ online]. Available from: Proquest.[http://search.proquest.com.libaccess.hud.ac.uk/docview/19 5990998? accountid=11526].

5. Dovaise, S. M. and Rahimpour, M. (2010). A Phonological Contrastive Analysis of Kurdish and English. International Journal of English Linguistics.December, 1 (2), pp. 73-82 [online] available from http://espace.library.uq.edu.au/view/UQ:259836]

6. Ellis, R. (1997). The Study of Second Language Acquisition. Oxford: Oxford University Press.

7. Fang, X. (2010). The Role of Input and Interaction in Second Language Acquisition/ LE ROLE D' INPUT D'INTERACTION DANS L'ACQUISITION D' UNE DEUXIEMELANGUE. March, 6 (1), pp.11-17 [online] Available: proquest.[http://search.proquest.com.libaccess.hud.ac.uk/docview/20 8600374? accountid=11526].

8. Fidler, A. (2006). Re-conceptualizing Fossilization in Second Language Acquisition: Review article. July. 22 (3), pp. 398-411 [ online] Available from: proquest. [http://search.proquest.com.libaccess.hud.ac.uk/docview/200185517? accountid=11526].

9. Gass, S. and Selinker, L. (2001). Second Language Acquisition: An Introductory Course. $2^{\text {nd }}$ ed. Mahwa, NJ: Lawrence Erlbaum and Associates.

10. Harmer, J. (2001). The Practice of English Language Teaching. $3^{\text {rd }}$ ed. England: Longman.

11. Jane, S. and Jennifer, J. (2005). State-of-the-Art Review article. Language Teaching. January. 38 (1), pp. 1-17 [ online] Available 
from:

Proquest.[http://search.proquest.com.libaccess.hud.ac.uk/docview/21 7737322? accountid=11526] .

12. Karen, C. (2011). The World Englishes Paradigm and its implications for International Students' Acquisition of Standard American English for university-level Studies in the United States. Published M.A. Dissertation and Thesis. Minnesota State University, Mankato.

13. Krashen, S. (1985). The Input Hypothesis: Issues and Implications. Harlow: Longman.

14. Krashen, S. (1982). Principles and Practice in Second Language Acquisition. Oxford: Pergamon.

15. Lantolf, J. D. and Beckett, T. G. (2004). Sociocultural Theory and Second Language Acquisition. Language Teaching. October. 42 (4), pp.

$459-475$.

[online]Available:proquest.[http://search.com.libaccess.hud.ac.uk/doc view/217760497?accountid=11526].

16. McLaughlin, B. (1987). Theories of Second Language Learning. London: Edward Arnold.

17. Lightbown, P. M. and Spada, N. (2006). How languages are learned. $3^{\text {rd }}$ ed. Oxford: Oxford University Press.

18. Louise, M. and Peter, S. (2010). Introducing English Language: A Source Book for Students. London: Rutledge.

19. Mitchell, R. and Myles, F. (2004). Second Language Learning Theories. $2^{\text {nd }}$ ed. London: Arnold.

20. Rutherford, W. and Thomas, M. (2001). The Child Language Data Exchange System in Search on Second Language Acquisition: Second Language Research. April. 17(2), pp.195-212 [ online] Available from:

proquest[http://search.proquest.com.libaccess.hud.ac.uk/docview/200 202213?accountid=11526].

21. Selinker, L et al (2004). Linguistic Structure with Processing in Second Language Research: Is a Unified Theory Possible? January. 20

pp.

77-94

[online]Available:proquest.[http://search.proquest.com.libaccess.hud. ac.uk/docview/200212907?accountid=11526].

22. Skinner, B. F. (1957). Verbal Behavior. New York: AppletonCentury-Crofts.

23. SLABAKOVA, R. (2008). Meaning in the Second Language, Studies in Language Acquisition Series, Berlin: Mouton de Gruyter. 
24. Smith, K. M. (2008). An exploration of Musical and Scaffolding in early Childhood. Published PhD, Dissertation and Thesis. University of Alberta (Canada).

25. Tedova, E. and Cenoz, J. (2009). The Multiple Realities of Multilingualism: Personal Narrative and Researcher's Perspectives (Trends in Applied Linguistics; 3). Berlin: Deutsche Nationalbibliothek.

26. Troike, S. M. (2006). Introducing Second Language Acquisition. Cambridge: Cambridge University Press.

27.TSIMPLI, I. M., \& DIMITRAKOPOULOU, M. (2007). The interpretabilityhypothesis: Evidence from wh-interrogatives in second language acquisition. Second Language Research, 23, 215242. 